\title{
AVALIAÇÃO DO MANEJO DE DESASTRES E PROTEÇÃO FINANCEIRA À INUNDAÇÃO NO VALE DO AÇU/RN
}

\author{
J. R. S. $\operatorname{COSTA}^{1{ }^{*}}$, A. H. M. SILVEIRA ${ }^{1}$, F. M. SILVA ${ }^{1}$ e H. J. A. FILGUEIRA ${ }^{2}$ \\ ${ }^{1}$ Dept. Geografia da Universidade Federal do Rio Grande do Norte \\ ${ }^{2}$ Dept. Engenharia Civil e Ambiental da Universidade Federal da Paraíba \\ rayssa480@hotmail.com*
}

Artigo submetido em setembro/2013 e aceito em agosto/2015

DOI: 10.15628/holos.2015.1634

\section{RESUMO}

Os municípios de Açu, Ipanguaçu, Alto do Rodrigues, Pendências e Carnaubais foram inundados diversas vezes, causado impactos econômicos, sociais e ambientais. Em virtude de tal situação se fez necessário realizar pesquisas para avaliar a vulnerabilidade e o risco existente à inundação nestas áreas. Neste sentido, este artigo objetiva expor a avaliação do manejo de desastres e governabilidade e proteção financeira no que concerne a inundação em municípios do Vale do Açu/RN por meio de Indicadores de Manejo de Desastres e de Governabilidade e Proteção Financeira. Como metodologia utilizou-se indicadores elaborados por Cardona (2005) por meio de questionários estruturados aos gestores municipais relativo à gestão institucional do ano de 2009. Como metodologia utilizou-se indicadores elaborados por Cardona (2005) por meio de questionários estruturados aos gestores municipais relativo à gestão institucional do ano de 2009. Os resultados mostram que os municípios que melhor manejam (IMD) e protegem financeiramente (IPF) os riscos à inundação respectivamente são: Açu (IMD e IPF qualificado como razoável), Ipanguaçu (IMD classificado como razoável e IPF - péssimo) e os demais municípios tanto o IMD como IPF foram ponderados como péssimos, devido ausência de algumas ações e recursos, como criação de fundo de investimentos sociais permanentes para o apoio de comunidades vulneráveis, com foco nos extratos socioeconômicos mais pobres e programas regulares de microcrédito, além de atividades do gênero, orientadas à redução da vulnerabilidade humana.

PALAVRAS-CHAVE: Risco; Vulnerabilidade; Desastre; Inundação; Gestão.

\section{DISASTER MANAGEMENT EVALUATION AND FINANCIAL PROTECTION TO FLOOD THE VALE DO AÇU/RN}

\begin{abstract}
The municipalities of Açu Ipanguaçu, Alto do Rodrigues, Pendências and Carnaubais were flooded several times, caused economic, social and environmental impacts. Because of this situation it was necessary to conduct research to assess the vulnerability and the existing risk to flooding in these areas. However, this article aims to expose the disaster management and governance/ and financial protection with regard to flooding by municipalities Vale do Açu/RN through Disaster Management Indicators and Governance and Financial Protection. The methodology we used indicators developed by Cardona (2005) through structured questionnaires to municipal managers on the
\end{abstract}

institutional management of 2009. The results show that the municipalities that better handles (IMD) and protects financially (IPF) the risk to flooding respectively are: Açu (IMD and qualified as reasonable IPF), Ipanguaçu (IMD classified as reasonable and IPF - bad) to the other municipalities both the IMD as IPF were weighted as terrible, due to the absence of some actions and resources, such as creating permanent social investment fund to support vulnerable communities, focusing on the poorest socioeconomic strata and regular microcredit programs, and activities gender, aimed at reducing human vulnerability.

KEYWORDS: Risk; vulnerability; disaster; flooding; Management. 


\section{INTRODUÇÃO}

As inundações são eventos que ocorrem frequentemente em várias partes do mundo, devido às chuvas rápidas e excessivas/intensas de longa duração que fazem parte da dinâmica natural da Terra. Sendo que, nas últimas décadas, a população tem sido afetada por este fenômeno de maneira desastrosa, cujo um dos maiores motivos é a ocupação desordenada do solo (COSTA, 2012), "tornando-se assim locais sensíveis às gradativas transformações antrópicas à medida que se intensificam em frequência e intensidade o desmatamento, a ocupação irregular, a erosão e o assoreamento dos canais fluviais" (GUERRA; CUNHA, 2006, p.30).

Para comprovar tal fato, Jonkman (2005) analisou os eventos de emergência do banco de dados de desastres mundial - EM-DAT (Emergency Events Database) mantido pelo Centro de Pesquisas sobre Epidemiologia dos Desastres (CRED) em Bruxelas, na Bélgica. O estudo revelou que, na última década do século 20 , problemas relacionados às inundações vitimaram cerca de 100 mil pessoas e afetaram mais de 1,4 bilhão em todo o mundo. O Programa das Nações Unidas para o Desenvolvimento (PNUD) registrou que, em 2004, cerca de 196 milhões de pessoas, em mais de 90 países, estavam expostas a uma inundação catastrófica e que cerca de 170.000 mortes foram associadas à inundação em todo o mundo, entre os anos de 1980 e 2000 (MACHADO; AHMAD, 2006, p.1 apud COSTA, 2012, p. 14).

Conforme estudo realizado pela Universidade Católica de Louvain (Bélgica), no Brasil, entre os anos 2000 a 2007, os desastres registrados foram causados por inundações (58\%), seguido das secas (14\%), deslizamentos (11\%), vendavais (8\%), temperaturas extremas (6\%) e epidemias (3\%) (MAFFRA; MAZOLLA, 2007, p.10).

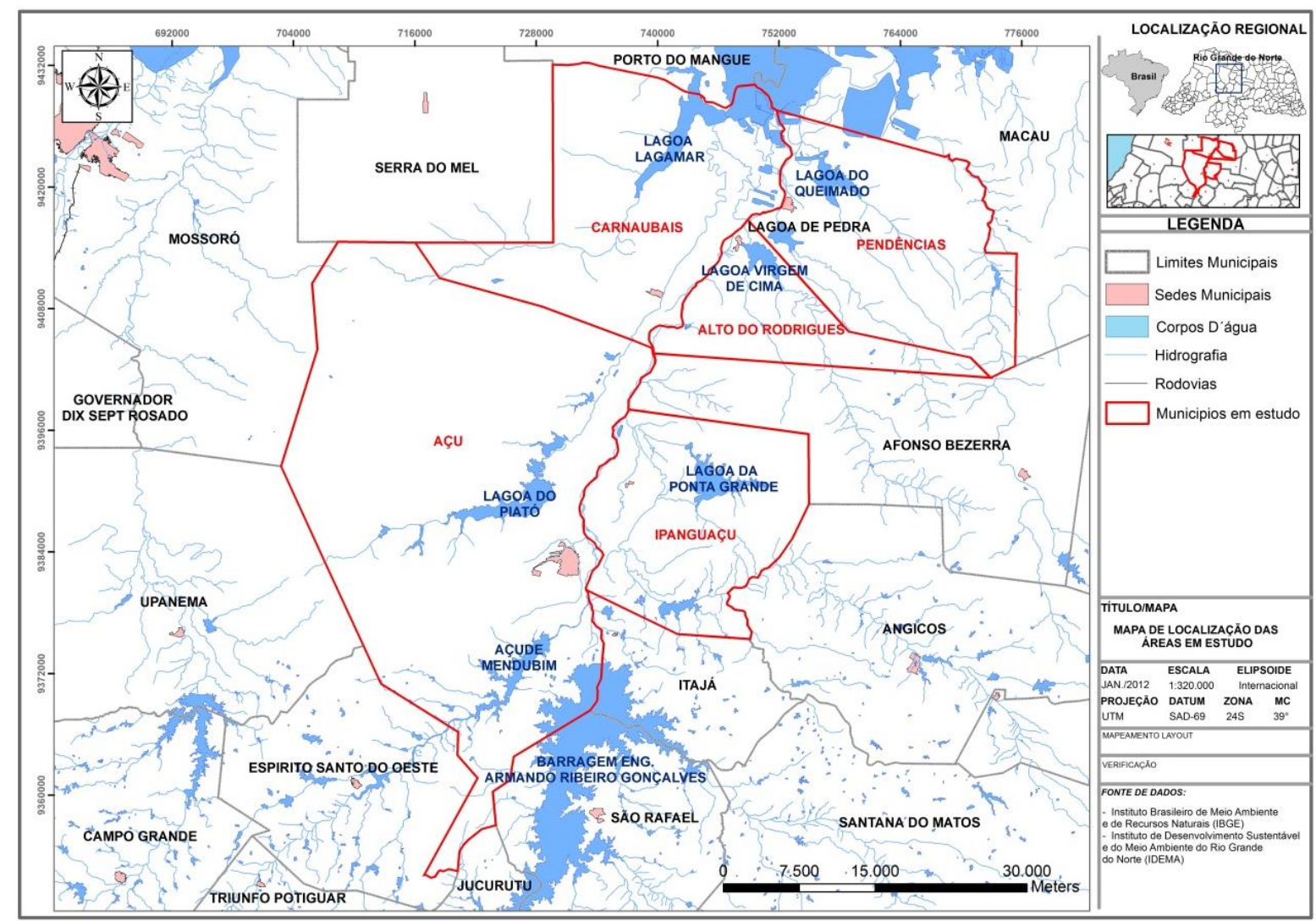

Figura 1: Mapa de localização dos municípios que compõe o Vale do Açu/RN e área de estudo. Elaboração: Iron Bezerra, nov, 2011. 


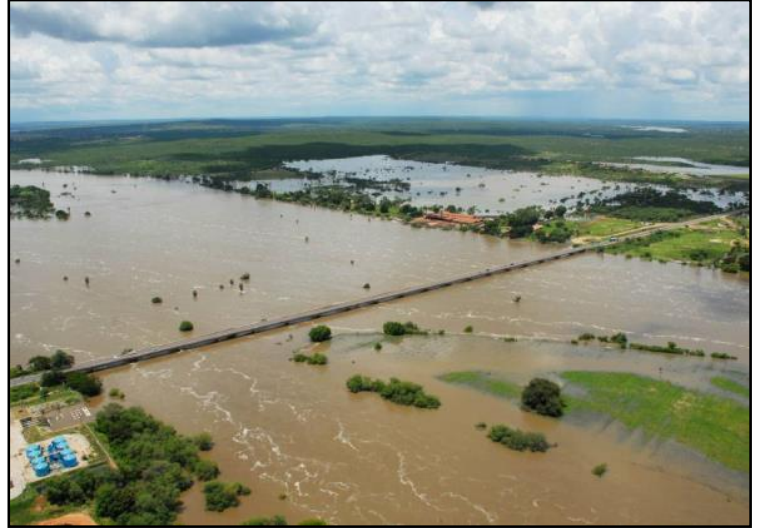

Figura 2: Ponte no município de Açu inundada Fonte: Moura, 2008.

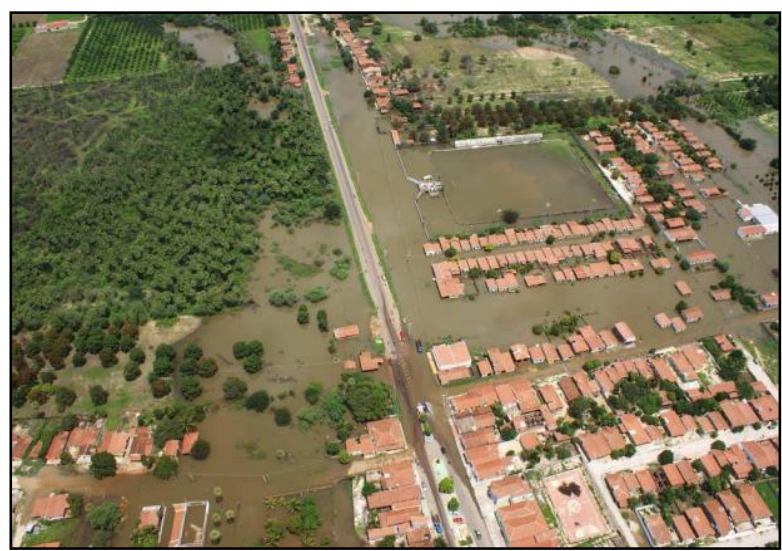

Figura 4: Área urbana de Ipanguaçu inundada Fonte: Moura, 2008.

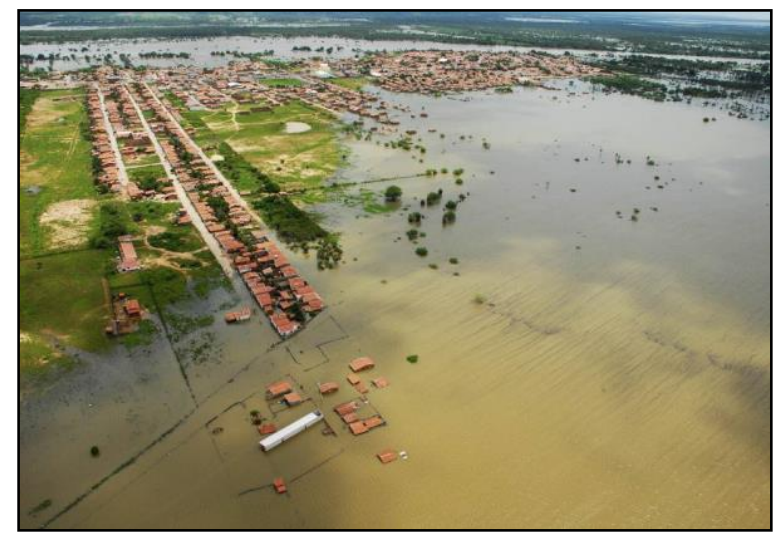

Figura 6: Área urbana de Alto do Rodrigues inundada. Fonte: Moura, 2008.

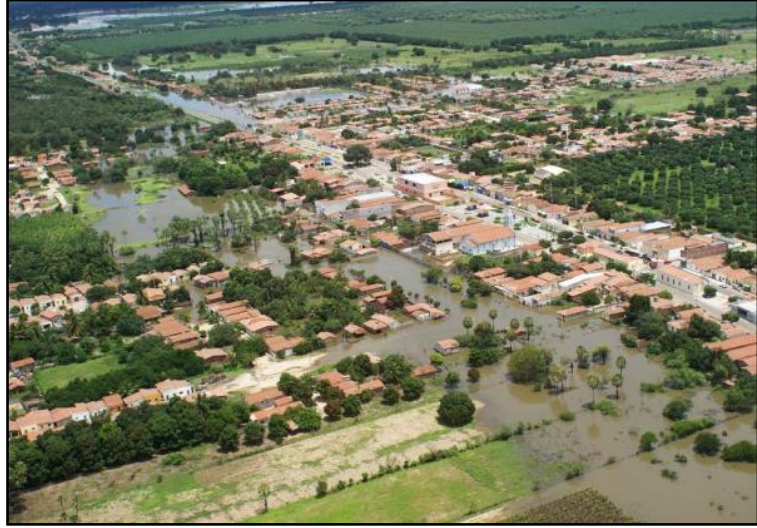

Figura 3: Núcleo urbano de Ipanguaçu inundado Fonte: Moura, 2008.

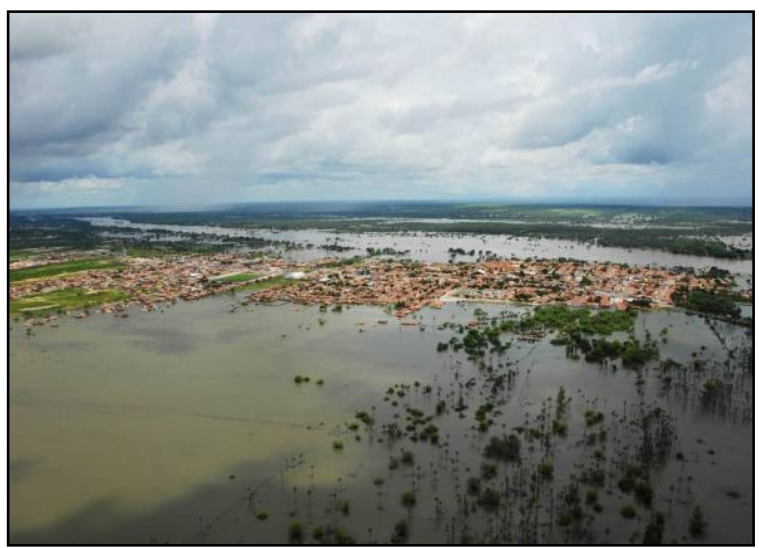

Figura 5: Cidade de Alto do Rodrigues inundada Fonte: Moura, 2008.

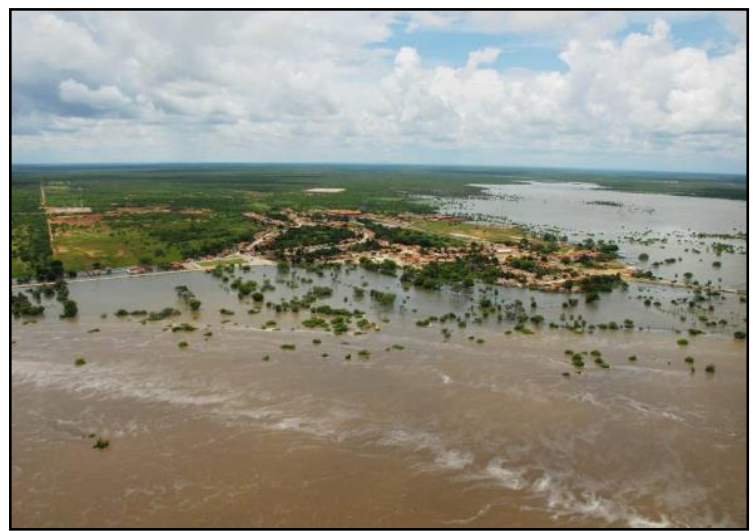

Figura 7: Núcleo urbano de Pendências inundado Fonte: Moura, 2008.

O Vale do Açu, situada na região centro-oeste do Estado do Rio Grande do Norte, Brasil, composta por municípios de Açu, Alto do Rodrigues, Carnaubais, Ipanguaçu, Itajá, Jucurutu, Pendências, Porto do Mangue e São Rafael (FIGURA 1), também sofre com ação de tal fenômeno, proveniente do extravasamento do leito do rio Açu causado pelas águas das chuvas e demais recursos hídricos existentes no entorno deste, com registros datados pela EMPARN em 1964, 1974, 1985, 2004, 2008 e 2009, cuja ação tem causado impactos em diversos setores 
(econômico, social e ambiental), e em várias escalas geográficas (local, regional, nacional e internacional), em virtude da economia estar voltada praticamente para a fruticultura nacional, principalmente para exportação.

Ao analisar a série histórica das inundações no Vale do Açu, verificou-se que tem ocorrido em prazos menores e com maior intensidade. Entre as 03 (três) primeiras inundações citadas, 0 tempo de retorno desse evento era entre 09 (nove) e 10 (dez) anos. Já entre 2004 e 2008 o tempo máximo sem a existência desse evento foi de 03 (três) anos. Após esse último ano, a inundação já ocorreu no ano seguinte. Das últimas 06 (seis) inundações nessa região, a de 2008 foi a que teve a menor precipitação pluviométrica anual $(778,1 \mathrm{~mm})$, porém foi a mais devastadora, enquanto que a de 2009 foi a segunda maior desse período (com um total de chuva de 1.126,9 mm), todavia os impactos não foram tão intensos (COSTA, 2009).

Contudo, a situação exposta acima revela que tal região é vulnerável a este fenômeno, pois, segundo Veyret (2007), a vulnerabilidade pode ser vista como perda de resiliência (VEYRET, 2007). E resiliência de acordo com a Organização das Nações Unidas para o Desenvolvimento PNUD (2004) é conceituada como a capacidade de um sistema, comunidade ou sociedade para resistir ou mudar no sentido de obter um nível aceitável de funcionamento e de estrutura. A resiliência é determinada pelo grau no qual o sistema social é capaz de se organizar, e a habilidade de ampliar sua capacidade de aprendizado e adaptação, inclusive de se recuperar de um desastre.

Devido à recorrência das inundações, é necessário avaliar a gestão (grau de vulnerabilidade e resiliência) dos riscos relacionados a este fenômeno, pois conforme Veyret (2007) reduzir a vulnerabilidade não consiste em tentar reduzir a frequência do evento adverso, o que é, em certos casos, totalmente impossível, mas em diminuir os efeitos possíveis da crise por meio do conhecimento dos processos e pela instalação de dispositivos adequados.

Contudo, Cardona (2005) investigaram e concluíram que não existiam indicadores específicos para avaliar diretamente o desempenho da gestão do risco. Em virtude de tal situação, elaboraram o Índice de Gestão de Riscos - IGR, baseado nas variáveis em escala qualitativa para verificar políticas públicas voltadas para: Identificação do Risco (IR), Redução do Risco (RR), Manejo de Desastre (MD) e Governabilidade e Proteção Financeira (PF).

Este índice encontra-se publicado no Programa de Indicadores de Riesgo de Desastre y Gestión de Riesgos na America Latina y Caribe, financiado pelo Banco Internacional de Desenvolvimento (BID) e Instituto de Desenvolvimento e Estudos Ambientais (IDEA), o qual é bastante eficiente e foi trabalhado por vários autores (CARREÑO et al., 2006a, 2006b, 2006c; ZAPATA-MARTÍ, 2007; CARREÑO et al., 2007a, 2007b; CARDONA, 2008).

Em virtude da metodologia de Cardona (2005) ser inovadora e não ter sido aplicada no Brasil até o momento, já que não existe banco de dados de desastres, como é o caso do International Emergency Disasters Database - EM-DAT mantido pelo Centro de Investigação sobre Epidemiologia dos Desastres (CRED) em Bruxelas, o qual possui dados mundial e do DESINVENTAR (Base de dados implementadas pelo grupo $L a$ Red de Estudos Sociais em Prevenção de Desastres na America Latina), o presente artigo visa expor os indicadores da gestão da inundação em municípios do Vale do Açu (Açu, Alto do Rodrigues, Carnaubais, Ipanguaçu e Pendências) por meio dos Indicadores de Manejo de Desastres (IMD) e Governabilidade e 
Proteção Financeira (IPF), os quais poderão auxiliar na tomada decisões tanto na esfera municipal, estadual e nacional.

\section{METODOLOGIA}

O método proposto por Cardona (2005) mede a gestão de risco devido a fenômenos naturais mediante indicadores algébricos, galgado em indicadores social, econômico e ambiental, transparentes, representativos e robustos, de fácil compreensão por parte dos representantes que formulam políticas públicas, a nível nacional, estadual e municipal. Estes dados são aplicados na equação:

$$
I G R_{M D, P F}=\left.\frac{\sum_{i=1}^{N} w_{i} \boldsymbol{I}_{i c}^{t}}{\sum_{i=1}^{N} w_{i}}\right|_{(M D, P F)}
$$

onde: $w_{i}$ é o peso designado a cada indicador, $I^{i}$ corresponde a cada indicador para cada unidade territorial em consideração " $\mathrm{c}$ " e o período " $\mathrm{t}$ " - normalizado e obtendo a desfusificação das valorizações linguísticas (péssimo, razoável, bom, ótimo e excelente) - que representam os níveis de desempenho da gestão de riscos definidos para cada política pública respectivamente, conforme Tabela 1.

Tabela 1: Classificação do Índice de Gestão de Riscos.

\begin{tabular}{|c|c|}
\hline Porcentagens & Classificação \\
\hline $0-20 \%$ & Péssimo \\
\hline $21-40 \%$ & Razoável \\
\hline $41-60 \%$ & Bom \\
\hline $61-80 \%$ & Ótimo \\
\hline $81-100 \%$ & Excelente \\
\hline
\end{tabular}

Fonte: Os autores.

Os dados municipais foram coletados junto aos coordenadores da Defesa Civil, com aplicação de questionários estruturados, envolvendo indicadores e níveis de desempenho, que podem ser visualizados nas Tabelas 2 e 3.

Tabela 2: Indicadores de Manejo de Desastres e de Governabilidade e Proteção Financeira

\begin{tabular}{|l|l|}
\hline \multicolumn{1}{|c|}{ Indicadores de Manejo de Desastres } & \multicolumn{1}{|c|}{$\begin{array}{c}\text { Indicadores de Governabilidade e Proteção } \\
\text { Financeira }\end{array}$} \\
\hline $\begin{array}{l}\text { IMD - 1. Organização e coordenação de operações de } \\
\text { emergências }\end{array}$ & $\begin{array}{l}\text { IPF - 1. Organização interinstitucional, multisetorial e } \\
\text { descentralizada }\end{array}$ \\
\hline $\begin{array}{l}\text { IMD - 2. Planejamento da resposta em caso de } \\
\text { emergência e sistemas de alerta }\end{array}$ & $\begin{array}{l}\text { IPF - 2. Fundos de reserva para o fortalecimento } \\
\text { institucional }\end{array}$ \\
\hline $\begin{array}{l}\text { IMD - 3. Dotação de equipes, ferramentas e } \\
\text { infraestrutura }\end{array}$ & $\begin{array}{l}\text { IPF - 3. Localização e mobilização de recursos de } \\
\text { orçamento }\end{array}$ \\
\hline $\begin{array}{l}\text { IMD - 4. Capacitação operativa, simulação e prova de } \\
\text { resposta interinstitucional }\end{array}$ & $\begin{array}{l}\text { IPF - 4. Implementações de redes e fundos de } \\
\text { segurança social }\end{array}$ \\
\hline $\begin{array}{l}\text { IMD - 5. Preparação e capacitação da comunidade } \\
\text { IPF - 5. Seguros e estratégias de transferências de } \\
\text { perdas ativas publicas }\end{array}$ \\
\hline $\begin{array}{l}\text { IMD - 6. Planejamento para a reabilitação e } \\
\text { reconstrução }\end{array}$ & $\begin{array}{l}\text { IPF - 6. Cobertura de seguros e resseguros de } \\
\text { habitação }\end{array}$ \\
\hline
\end{tabular}

Fonte: Cardona (2005). 
Tabela 3: Níveis de desempenho, qualificação e características dos níveis de desempenho

\begin{tabular}{|c|c|c|}
\hline Níveis de desempenho & Qualificação & Características dos níveis de desempenho \\
\hline 0 & Péssimo & Não constava nenhuma informação do que foi solicitado. \\
\hline 1 & Ruim & Apresentava dados básicos (incipientes). \\
\hline 2 & Razoável & Proporcionava informações consideráveis. \\
\hline 3 & Bom & Dispunha de subsídios importantes. \\
\hline 4 & Ótimo & Oferecia varias condições. \\
\hline 5 & Excelente & Continha os melhores recursos. \\
\hline
\end{tabular}

Fonte: Os autores, 2011.

\section{RESULTADOS E DISCUSSÕES}

$\mathrm{Na}$ Tabela 4 consta a porcentagem da gestão do manejo de desastre e proteção financeira, os quais são oriundos dos níveis de desempenhos ponderados pelos gestores municipais. Após a Tabela 4 encontra-se a justificativa das ponderações.

Tabela 4: Porcentagem dos indicadores em análise para as áreas em questão.

\begin{tabular}{|c|c|c|c|c|}
\hline Municípios & IMD* $(\%)$ & Classificação & IPF** $(\%)$ & Classificação \\
\hline Pendências & 13,9 & Péssimo & 11,1 & Péssimo \\
\hline Alto do Rodrigues & 8,3 & Péssimo & 11,1 & Péssimo \\
\hline Carnaubais & 5,6 & Péssimo & 11,1 & Péssimo \\
\hline Ipanguaçu & 30,6 & Razoável & 16,7 & Péssimo \\
\hline Açu & 27,8 & Razoável & 22,2 & Razoável \\
\hline
\end{tabular}

* Indicadores de Manejo de Desastres e **Indicadores de Governabilidade e Proteção Financeira.

Fonte: Os autores, 2011.

O primeiro indicador analisado com relação a essa temática foi a Organização e coordenação de operações de emergência (IMD - 1), conforme apresentado na Tabela 2, no qual o município de Alto do Rodrigues e Carnaubais encontram-se ponderados pelo número 1 e considerados como péssimo, pois não existe uma equipe multiprofissional capacitada e locais apropriados para atender operações de emergências no período de inundação.

Pendências e Açu foram ponderados com 3 e qualificados como bons, pois apresentaram uma coordenação apreciável em algumas localidades da cidade, entre as entidades operativas na preparação conjunta, comunicação, busca e resgate, rede de urgências e gestão de alojamentos temporais. Ipanguaçu foi avaliado com 5 e classificado como excelente, pois oferece protocolos adequados de coordenação permanente para responder em caso de emergência entre as entidades operativas de serviços públicos, às autoridades locais e população na maioria das localidades.

No que concerne ao Planejamento da resposta em caso de emergência e sistemas de alerta (IMD - 2), o município de Açu foi o único ponderado com 1 e classificado como ruim, pois apresentava apenas um Plano de Contingência básico. Para ser elevado de qualificação precisará elaborar melhor os procedimentos operativos e de informação à comunidade, assim como ser bem definidos na cidade, com sistemas de prognóstico e alerta operando no período de inundação. Quanto aos demais, não havia nenhum método de ação e informação às 
comunidades bem definidos na cidade, sendo assim ponderados com 0 e classificados como péssimos.

Quanto à Dotação de equipes, ferramentas e infraestrutura (IMD - 3), o município de Ipanguaçu foi o único dentre os analisados que apresentou equipe especializada em emergência em algumas localidades e distritos e também realizou inventários de recursos de outras entidades públicas, sendo ponderado por 2 e qualificado como razoável. Os demais foram avaliados com 1 e qualificados como ruins, pois apresentavam uma reserva básica para dotação de equipes, ferramentas e infraestrutura. Deveriam apresentar redes de apoio interinstitucional, centros de reservas e outros Centros de Operações de Emergência (COEs), com amplas facilidades de reporte, comunicações, transporte e abastecimento em caso de emergência.

Referente à Capacitação operativa, simulação e prova de resposta interinstitucional (IMD - 4), o município de Carnaubais foi ponderado como 0 e classificado como péssimo, pois não participou de nenhum programa de capacitação em 2009. Os demais foram qualificados como 1 e classificados como ruins, pois apesar de terem participado de algum programa de capacitação, não realizaram simulação da resposta institucional em nível interno de cada entidade e em conjunto entre várias entidades operativas da cidade e não elaboraram treinamento permanente de grupos de resposta, prova de planos de emergência e contingência e atualização de procedimentos operativos, com base em exercícios de simulação na maioria das localidades, para que assim possam subir de qualificação.

Concernente à preparação e capacitação da comunidade (IMD - 5), todos os municípios foram ponderados com 0 e qualificados como péssimos, pois não desenvolveram reuniões informativas e cursos esporádicos com comunidades para ilustrar o que se deve fazer em emergência quando ocorrem desastres.

No que tange ao planejamento para a reabilitação e reconstrução (IMD - 6), os municípios de Pendências, Alto do Rodrigues e Carnaubais foram avaliados com 0 e classificados como péssimos, pois não elaboram desenho e implementação de planos de reabilitação e reconstrução nem posteriormente aos desastres.

Ipanguaçu encontra-se ponderado com o número 3 e classificado como bom, pois procedeu com restabelecimento e reparação de infraestrutura e programas de projetos produtivos para a recuperação de comunidades.

Açu foi ponderado com 4 e classificado como ótimo, pois realizaram planos e programas para a recuperação do tecido social, fontes de trabalho e de meios produtivos das comunidades, por meio de cursos de qualificação da mão de obra (fruticultura, pedreiro, eletricista, encanador), doação de terrenos para que pequenas oficinas e empresas pudessem gerar emprego (direto e indireto e renda), além de Programa da Revitalização da Cultura do Algodão, no qual onde conseguiram na safra do ano de 2010/2011 fazer com que mais de 120 produtores de Açu e num total de 160 do Vale do Açu produzissem mais de 300ha de algodão, gerando renda para a agricultura familiar.

Ao analisar o indicador organização interinstitucional, multisetorial e descentralizada (IPF - 1), o qual faz parte das políticas públicas voltadas para Governabilidade e Proteção Financeira, observa-se que os municípios de Pendências, Alto do Rodrigues e Carnaubais encontram-se ponderado por 1 e qualificados como ruins, pois apresentam apenas uma organização básica de 
entidades em comitê e com um enfoque de resposta à emergências. Ipanguaçu e Açu foram ponderados com 3 e qualificados como bom, devido possuírem um sistema interinstitucional de gestão de risco ativo, com trabalho para desenho de políticas públicas sobre redução de vulnerabilidade.

Quanto aos Fundos de reserva para o fortalecimento institucional (IPF - 2), todos os municípios foram ponderado com 1 e classificados como ruins, pois nenhum apresentou fundo de reservas da cidade.

No que tange à localização e mobilização de recursos do orçamento (IPF - 3), todos os territórios em análise foram ponderados como 0 e qualificados como péssimos, pois contam com nenhuma atribuição limitada de partidas orçamentais, apenas remanejam recursos financeiros de outros setores para a defesa civil, com fins de atenção de emergências e não de prevenção.

Concernente a Implementações de redes e fundos de segurança social (IPF - 4), o município de Açu foi ponderado como 3 e classificado como bom, pois neste existe realização de redes sociais para auto proteção dos meios de sustento de comunidades em risco e realização de projetos produtivos de reabilitação e recuperação pós-desastre.

Referente aos Seguros e estratégias de transferências de perdas ativas públicas (IPF - 5) e Cobertura de Seguros e Resseguros de Habitação (IPF - 6), todos os municípios foram avaliados com 0 e qualificados como péssimo, pois nenhum realizou seguro dos imóveis públicos e de moradias.

No que concerne ao Manejo a Desastres, a maiorias dos municípios foram classificados entre péssimo e ruim, visto que a coordenação de operações de emergência atendia sem maiores recursos e sem levantamento de recursos necessários. Além desse fator, os municípios não continham Plano de Contingência, exceto Açu. Em muitos não havia plano de reabilitação e reconstrução de moradias, sendo Ipanguaçu e Açu exceções neste quesito.

Um fator preocupante diagnosticado refere-se à preparação e capacitação da comunidade, as quais foram inexistentes em todos os municípios, apenas existiam conversas informais sobre este assunto e próximo ao acontecimento da inundação.

Quanto ao quesito Governabilidade e Proteção Financeira estão extremamente precários, pois nos municípios não havia fundos para desastres, inexistência de seguros de imóveis públicos, moradias e infraestruturas públicas. Os recursos são limitados e dispostos apenas para atender em período de emergência e a organização interinstitucional geralmente é centralizada na Defesa Civil, as quais geralmente são compostos por diversos profissionais (enfermeiros, assistentes sociais, técnicos em meio ambiente e dentre outros), o que representa um ponto positivo.

\section{CONCLUSÕES}

De maneira geral, os municípios estudados no Vale do Açu, RN, não estão preparados para situações de desastres à inundação em seus territórios.

Há uma carência em todos os municípios analisados de uma equipe multiprofissional capacitada e locais apropriados para atender as operações de emergências no período de inundação. 
Isso também se verifica para as atividades de prevenção e preparação para o risco de desastres por inundação, pois apenas o município de Açu apresentou um plano de contingência, porém ainda muito incipiente.

Nenhum dos municípios apresentou um plano de atividades de informação com as comunidades, para ilustrar o que se deve fazer em emergências na ocorrência de um desastre.

Quanto ao planejamento para a reabilitação e reconstrução, os municípios de Pendências, Alto do Rodrigues e Carnaubais foram classificados como péssimos, pois não elaboram desenho e implementação de planos de reabilitação e reconstrução nem posteriormente aos desastres.

Ipanguaçu nesse item foi classificado como bom, pois apresentou programas de restabelecimento e reparação de infraestrutura e projetos produtivos para a recuperação de comunidades. Já o município de Açu foi classificado como ótimo, pois realizaram planos e programas para a recuperação do tecido social, fontes de trabalho e de meios produtivos nas comunidades, gerando renda para a agricultura familiar.

Para o indicador organização interinstitucional, multisetorial e descentralizada, os municípios de Pendências, Alto do Rodrigues e Carnaubais foram qualificados como ruins, pois apresentam apenas uma organização básica de entidades em comitê e com um enfoque apenas para a resposta à emergências. Ipanguaçu e Açu foram qualificados como bom devido terem um sistema interinstitucional de gestão de risco ativo, porém com uma carência muito expressiva de gestão propriamente dita nas fases antes, durante e depois da ocorrência de um desastre.

Não há fundos de reserva para o fortalecimento institucional em todos os municípios. Apenas remanejam recursos financeiros de outros setores para a defesa civil, com fins de atenção de emergências e não de prevenção.

Todos os municípios analisados estão extremamente precários quanto ao quesito Governabilidade e Proteção Financeira, pois também não há fundos para desastres, inexistência de seguros de imóveis públicos, moradias e infraestruturas públicas.

\section{REFERÊNCIAS BIBLIOGRÁFICAS}

1. CARDONA, O.D. Indicators of disaster risk and risk management: main tecnical report. Washington, D.C.: National University os Colombia - Manizales, Institute Of Environmental Studies, Inter-American Development Bank, 2005.

2. CARDONA, O.D. Medición de la gestión del riesgo en América Latina. Revista Internacional de Sustenibilidad, Tecnologia e Humanismo.n. 3, p. 1-20, 2008.

3. CARREÑO, M.L.T. Técnicas innovadoras para La evaluación Del riesgo sísmico y sugestión en centros urbanos: Acciones ex ante y ex post. Tesisdoctoral, Universidad Politécnica de Cataluña, Barcelona, 2006a.

4. CARREÑO, M.L.T., CARDONA, O.D, BARBAT, A.H.Evaluation of the risk management performance.2006b.

5. CARREÑO, M.L.T., CARDONA, O.D., MARULANDA, M.C.F., BARBAT, A.H. Índice para medir el desempeño de La gestión de riesgos. Revista Internacional de Ingeniería de Estructuras. v. 11. n. 1, p. 25-44, 2006c. 
6. CARREÑO, M.L.T., CARDONA, O.D, MARULANDA, M.C.F.; BARBAT, A.H. Índice para evaluar EI desempeño y La efectividad de la gestión de riesgos (DRMi). AsociaciónEspañola de Ingeniería Sísmica Girona, 8-11, mayo, 2007a.

7. CARREÑO, M.L.T., CARDONA, O.D, BARBAT, A.H. A disaster risk management performance index. Nat Hazards, v. 41, p. 1-20, february, 2007b.

8. COSTA, J.R.S. Análise ambiental das inundações no município de Ipanguaçu/RN no ano de 2008 e 2009 e suas repercussões socioeconômicas. Natal, 2009. Monografia-Departamento de Geografia-Universidade Federal do Rio Grande do Norte, 2009.

9. COSTA, J.R.S.C. Análise da vulnerabilidade e gestão de risco a desastres por inundação em municípios do Vale do Açu/RN. João Pessoa, 2012. Dissertação de Mestrado-Departamento de Engenharia Civil, Universidade Federal da Paraíba, 2012.

10. EMPARN. Empresa de Pesquisas Agropecuárias do Rio Grande do Norte. Dados meteorológicos do município de Ipanguaçu/RN no período de 1964 a 2009.

11. GUERRA, A. J. T; CUNHA, S. B. Impactos ambientais urbanos no Brasil. Rio de Janeiro: Bertrand Brasil, 2006.

12. MAFFRA, C.Q.T., MAZOLLA, M. As razões dos desastres em território brasileiro. IN: SANTOS, Rozely Ferreira dos (Org.) Vulnerabilidade Ambiental: desastres naturais ou fenômenos induzidos?. Brasília, Ministério do Meio Ambiente, 2007.

13. MOURA, G. Água: sobrevôo fotográfico sobre os efeitos das chuvas nos rios e nas cidades do Vale do Açu, da Barragem Armando Ribeiro até o litoral. 2008. Disponível em: <rayssa480@hotmail.com>. Acesso em: 15 abr. 2008.

14. VEYRET, Y. (org.). Os riscos: o homem como agressor e vítima do meio ambiente. São Paulo: Contexto. 2007.

15. ZAPATA-MARTÍ, R. Información para la gestión de riesgo de desastres. Estudios de caso de cinco países: Informe resumido. 2007. 